\title{
ESTUDO DAS INUNDAÇÕES NA CIDADE DE SÃO GABRIEL, RS
}

\author{
STUDY OF FLOODING IN THE CITY OF SAN GABRIEL, RS
}

\author{
Vanessa Salvadé Silveira \\ Universidade do Federal de Santa Maria (UFSM), Santa Maria, RS, Brasil, vanessasalvadesilveira@gmail.com \\ Luis Eduardo de Souza Robaina \\ Universidade do Federal de Santa Maria (UFSM), Santa Maria, RS, Brasil, lesrobaina@yahoo.com.br \\ Romário Trentin \\ Universidade do Federal de Santa Maria (UFSM), Santa Maria, RS, Brasil, romario.trentin@gmail.com
}

\begin{abstract}
RESUMO
O presente trabalho tem como objetivo analisar os eventos de inundação na cidade de São Gabriel. Primeiramente, criou-se um inventário sobre os processos associados à inundação na cidade, foi realizado entre os anos de 1980 a 2009. Estas informações serviram de base para identificar o comportamento temporal e espacial das inundações que afetaram a área urbana de São Gabriel no período estudado. A análise buscou relacionar os dados de precipitação de estações pluviométricas no município com dados de cota de uma estação fluviométrica no rio Vacacaí. Os dados hidrológicos referente à cota altimétrica do rio Vacacaí e as precipitações que atingiram o município durante os eventos de inundações foram coletados no site do HidroWeb (http://hidroweb.ana.gov.br/) da Agência Nacional de Águas (ANA). A partir destas análises verificaram-se eventos importantes, como por exemplo, o evento que ocorreu em maio de 1984 em que o rio Vacacaí atingiu $502 \mathrm{~cm}$. Com isso, sabe-se a menor cota em que um evento é confirmado. Outro evento importante é o ocorrido em novembro de 1990, que se mostra um dos mais significativos dentro do histórico de inundação da cidade por apresentar uma das mais altas cotas de elevação das águas do rio Vacacaí, sendo que esta atingiu $810 \mathrm{~cm}$.
\end{abstract}

Palavras-chave: Inundação. São Gabriel. Vacacaí.

\section{ABSTRACT}

This study aims to analyze the flood events in the city of São Gabriel. First, we created an inventory of the processes associated with the flooding in the city, was conducted between 1980 and 2009. This information formed the basis for identifying the temporal and spatial behavior of the floods that affected the urban area of São Gabriel in the period studied. The analysis tried to correlate rainfall data from rain gauge stations in the county with a data quota fluviometric station in Vacacai river. The hydrologic data related to altimetry Vacacai the river and rainfall that hit the city during the flood events were collected in the HIDROWEB site (http://hidroweb.ana.gov.br/) of the National Water Agency (ANA). From these analyzes there were significant events, such as the event that occurred in May 1984 when the river reached $502 \mathrm{~cm}$ Vacacaí. With this, it is known to lower elevation at which an event is confirmed. Another important event is held in November 1990, which shows the most significant within the historic flooding of the city by presenting one of the highest quotas rising waters of the river Vacacaí, and this reached $810 \mathrm{~cm}$.

Keywords: Flood. San Gabriel. Vacacaí.

Artigo recebido para publicação em novembro de 2014

Artigo aceito para publicação em junho de 2015

\section{INTRODUÇÃO}

As inundações são responsáveis por um número elevado de perdas de vidas humanas e materiais todos os anos. Consideradas como um fenômeno de natureza hidro meteorológica, estas fazem parte da dinâmica natural e ocorrem, principalmente, deflagradas por chuvas rápidas e fortes, chuvas intensas 
de longa duração e outros eventos climáticos tais como furacões e tornados, podendo ser intensificadas por ações antrópicas (IPT, 2007, p. 89).

Reckziegel (2007, p.110), em seu trabalho sobre Desastres Desencadeados por Eventos Naturais no Estado do Rio Grande do Sul, apontou para o período de 1980 a 2005 o registro de 1.258 ocorrências de desastres desencadeados por enchentes, sendo que foram homologados 571 decretos de Situação de Emergência e 42 de Estado de Calamidade Pública. Das cidades afetadas do estado, São Gabriel é apontada no trabalho como uma das mais atingidas por estes eventos.

Desta forma o presente trabalho tem como objetivo analisar os eventos de inundação na cidade de São Gabriel. De um modo geral, o monitoramento e análise das cheias dos rios facilita a convivência com o fenômeno (CASTRO, 2003, p. 48). Portanto, identificar os anos de ocorrência dos eventos de inundação na cidade de São Gabriel com informações sobre cotas e o volume de precipitações, associadas aos eventos, é uma ferramenta fundamental para a previsão, assim como, contribuir para a redução de possíveis danos e prejuízos.

O município de São Gabriel está localizado na região central do estado do Rio Grande do Sul (Figura 1), a 320 quilômetros de Porto Alegre. Segundo dados do IBGE (2010), apresenta uma população total de 60.508 habitantes, com 53.860 habitantes (mais de 80\%) na área urbana. Parte desta população se localiza no entorno do Rio Vacacaí e tem sido afetada seguidamente por eventos de inundação. 


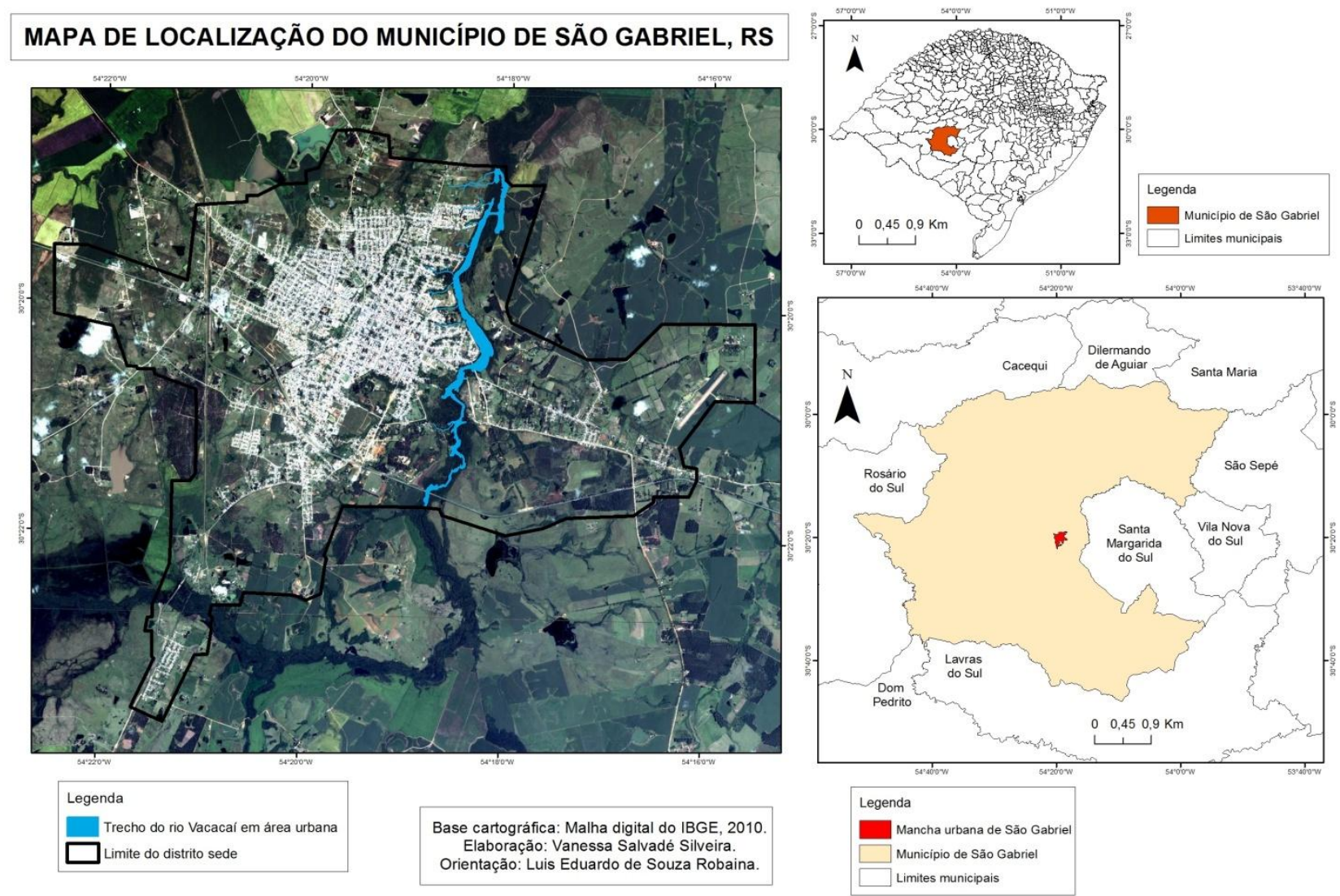

Figura 1. Mapa de localização do município com sua área urbana.

\section{METODOLOGIA}

O inventário sobre os processos associados à inundação, na cidade de São Gabriel, foi realizado entre os anos de 1980 a 2009. Os dados gerais do período de ocorrência de cada evento foram coletados na dissertação de mestrado de Reckziegel (2007), na Defesa Civil Estadual e na imprensa local com o Jornal Imparcial. Estas informações serviram de base para identificar o comportamento temporal e espacial das inundações que afetaram a área urbana de São Gabriel no período estudado.

Com a identificação dos bairros que apresentaram registro de eventos possibilitou-se localizar as áreas sujeitas à ocorrência do fenômeno.

Os dados hidrológicos referente à cota altimétrica do rio Vacacaí e as precipitações que atingiram o município durante os eventos de inundações foram coletados no site do HidroWeb (http://hidroweb.ana.gov.br/) da Agência Nacional de Águas (ANA). 
As estações obtidas no portal referentes à precipitação são, no total, quatro, sendo elas: Estação da ANA 03053019 (Colônia Pavão), coordenadas 3000'00”S / 5356’00”W; Estação ANA 03054018 (São Gabriel), coordenadas 30²1’27”S / 5419’50”W; Estação ANA 03053004 (Passo do Rocha), coordenadas 30²13'57'S / 53ํ5'36”W e Estação ANA 03054020 (RS-473),

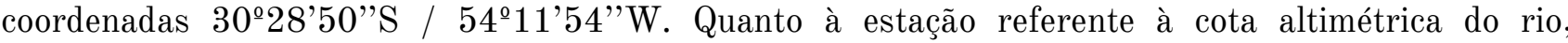
apresenta-se apenas uma, sendo ela: Estação ANA 85470000 (Ponte São Gabriel), coordenadas $30^{\circ} 21^{\prime} 35^{\prime \prime} \mathrm{S} / 54^{\circ} 18^{\prime} 48^{\prime \prime} \mathrm{W}$ (Figura 2).

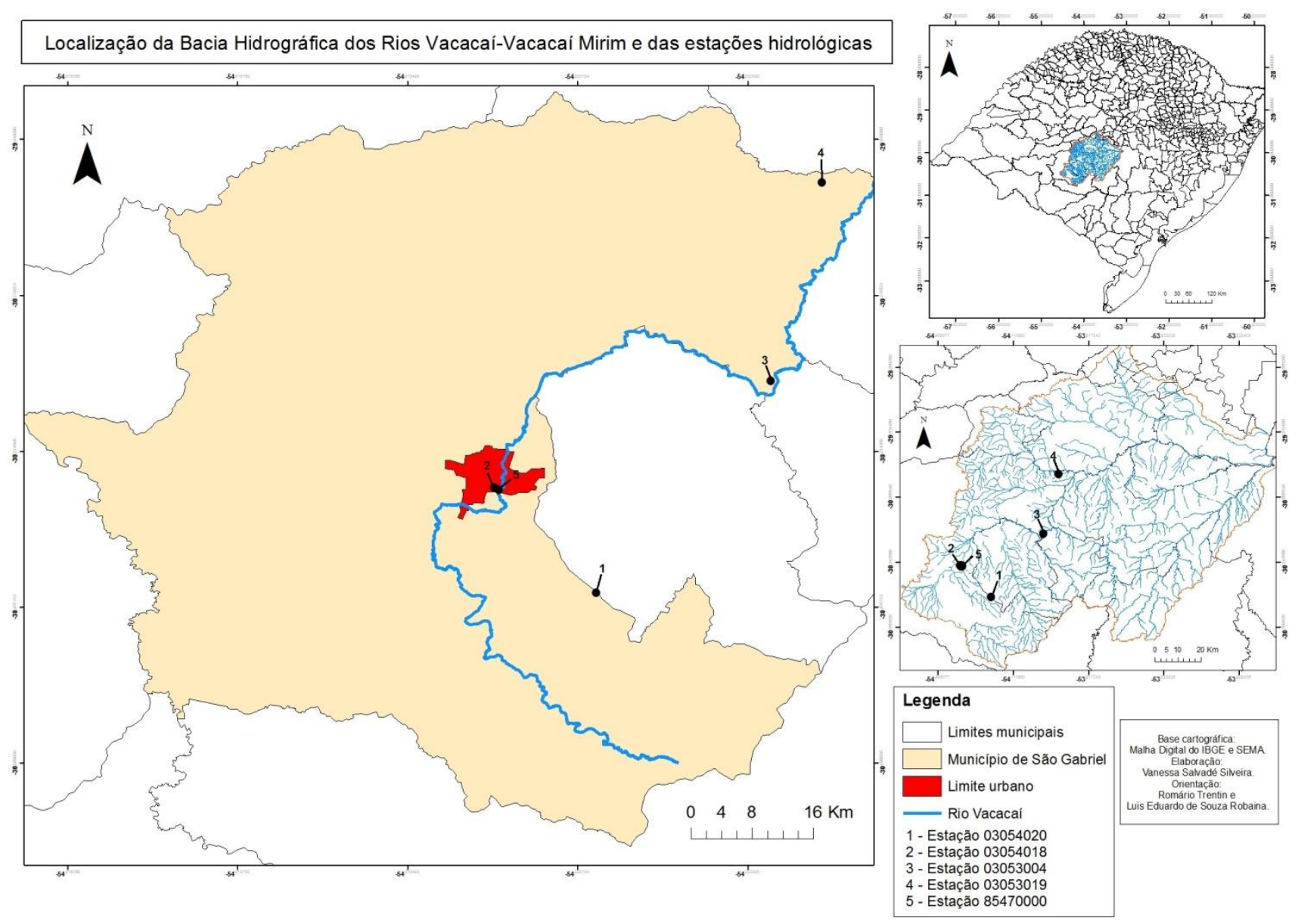

Figura 2. Mapa de localização da Bacia Vacacaí-Vacacaí Mirim e das estações hidrológicas.

Visando estabelecer uma correlação com os eventos de El Niño, utilizou-se a classificação estabelecida pelo CPTEC-INPE e pelo Climate Prediction Center que estabelecem uma definição da intensidade dos eventos quanto ao grau fraco, moderado ou forte. 
Em trabalhos de campo foi possível verificar as áreas dos limites de inundação com auxílio de equipamento de posicionamento global. A utilização do software ArcGis 9.3 permitiu a organização de um banco de dados com as informações do fenômeno.

O zoneamento de risco de inundação foi realizado através da análise da probabilidade de ocorrência do fenômeno de inundação e da vulnerabilidade da população afetada.

A probabilidade de ocorrência do fenômeno foi determinada a partir do cruzamento entre as variáveis: frequência dos eventos, mapa de suscetibilidade determinado pela identificação da planície de inundação, e mapa da área urbana.

A partir da integração dessas informações foram definidos dois diferentes níveis de perigo de inundação em termos de probabilidade espacial e temporal na área de estudo, conforme mostra o Quadro 1.

\begin{tabular}{|c|c|}
\hline Classe & Descrição \\
\hline Alta & $\begin{array}{r}\text { Áreas urbanas na planície de inundação com alta probabilidade temporal e } \\
\text { espacial de serem atingidas por inundações }\end{array}$ \\
\hline Baixa & $\begin{array}{r}\text { Áreas urbanas na planície de inundação com alta probabilidade temporal e } \\
\text { espacial de serem atingidas por inundações }\end{array}$ \\
\hline
\end{tabular}

Quadro 1. Descrição e peso das classes de perigo à inundações.

A vulnerabilidade foi estabelecida, a partir da identificação da área de perigo, através da determinação das características da população que sofre o dano, sua capacidade de intervenção ao evento. Para isso, definiu-se o tipo de moradia e as condições gerais das áreas afetadas pelas inundações.

A partir da integração dessas informações, foram determinados diferentes níveis de vulnerabilidade a inundações em termos de probabilidade de ocorrência espacial e temporal e pela probabilidade de danos na área de estudo, como mostra o Quadro 2. 


\begin{tabular}{|c|c|}
\hline Classe & Descrição \\
\hline \multirow{2}{*}{ Alta } & $\begin{array}{c}\text { Áreas urbanas com baixo-muito baixo padrão de moradias, adensamento, } \\
\text { relativamente alto, baixa capacidade de ações contra inundações. }\end{array}$ \\
\hline \multirow{3}{*}{ Média } & $\begin{array}{c}\text { Áreas urbanas com médio-baixo padrão de moradias, adensamento, } \\
\text { relativamente, alto e é possível observar algumas ações estruturais, } \\
\text { localizadas, contra inundações. }\end{array}$ \\
\hline \multirow{2}{*}{ Baixa } & Áreas urbanas com padrão construtivo médio, mais elevado ou um número \\
reduzido de moradias atingidas.
\end{tabular}

Quadro 2. Descrição e peso das classes de vulnerabilidade a inundações.

O zoneamento do risco foi realizado a partir do cruzamento dessas informações indicando diferentes níveis de risco a inundações em termos de probabilidade de ocorrência e de danos, como mostra 0 Quadro 3.

\begin{tabular}{|c|c|}
\hline Classe & Descrição \\
\hline $\begin{array}{c}\text { Muito } \\
\text { Alta }\end{array}$ & $\begin{array}{c}\text { Áreas urbanas com alta probabilidade de ocorrência de inundações, onde são } \\
\text { esperadas altas ou muito altas consequências de danos e prejuízos. }\end{array}$ \\
\hline Alta & $\begin{array}{c}\text { Áreas urbanas com alta probabilidade de ocorrência de inundações, onde são } \\
\text { esperadas médias consequências de danos e prejuízos. }\end{array}$ \\
\hline Média & $\begin{array}{c}\text { Áreas urbanas com baixa probabilidade de ocorrência de inundações, mas são } \\
\text { esperadas médias ou altas consequências de danos e prejuízos; ou Áreas } \\
\text { urbanas com alta probabilidade de ocorrência de inundações, mas são esperadas } \\
\text { baixos danos e prejuízos. }\end{array}$ \\
\hline Baixa & $\begin{array}{c}\text { Áreas urbanas com baixa probabilidade de ocorrência de inundações, onde são } \\
\text { esperadas baixas consequências de danos a prejuízos. }\end{array}$ \\
\hline
\end{tabular}

Quadro 3. Descrição e peso das classes de risco à inundações.

\section{INUNDAÇÕES EM SÃO GABRIEL}

\section{Caracterização temporal e espacial dos eventos}

Os registros de inundações no município de São Gabriel apontam no geral 30 eventos de inundação do ano de 1980 a 2009 , como mostra o Quadro 4. 


\begin{tabular}{|c|c|c|}
\hline Ano & Mês & Decreto \\
\hline 1982 & Novembro & Sem decreto \\
\hline \multirow{2}{*}{1983} & Fevereiro & Sem decreto \\
\cline { 2 - 3 } & Maio & Sem decreto \\
\cline { 2 - 3 } & Julho & Situação de Emergência \\
\hline \multirow{2}{*}{1984} & Maio & Sem decreto \\
\cline { 2 - 3 } & Maio & Situação de Emergência \\
\cline { 2 - 3 } & Junho & Sem decreto \\
\hline 1985 & Agosto & Sem decreto \\
\hline \multirow{2}{*}{1986} & Abril & Sem decreto \\
\cline { 2 - 3 } & Novembro & Sem decreto \\
\hline \multirow{2}{*}{1987} & Janeiro & Sem decreto \\
\cline { 2 - 3 } & Abril & Situação de Emergência \\
\hline \multirow{2}{*}{1990} & Abril & Sem decreto \\
\cline { 2 - 3 } & Novembro & Situação de Emergência \\
\hline 1991 & Abril & Sem decreto \\
\hline 1992 & Abril & Sem decreto \\
\hline 1993 & Novembro & Situação de Emergência \\
\hline 1994 & Outubro & Sem decreto \\
\hline \multirow{2}{*}{1997} & Novembro & Situação de Emergência \\
\cline { 2 - 3 } & Dezembro & Situação de Emergência \\
\hline \multirow{3}{*}{1998} & Fevereiro & Sem decreto \\
\cline { 2 - 3 } & Abril & Sem decreto \\
\cline { 2 - 3 } & Junho & Sem decreto \\
\cline { 2 - 3 } & Agosto & Situação de Emergência \\
\hline 2001 & Outubro & Sem decreto \\
\hline \multirow{2}{*}{2009} & Setembro & Sem decreto \\
\cline { 2 - 3 } & Outubro & Situação de Emergência \\
\hline \multirow{2}{*}{ Novembro } & Sem decreto \\
\hline \multirow{2}{*}{ Dezembro } & Sem decreto \\
\hline \multirow{2}{*}{19 Situação de Emergência } \\
\hline
\end{tabular}

Quadro 4. Relação dos anos e meses dos eventos de inundação decretos de situação de emergência.

Nos anos 80, as inundações ocorridas nos anos de 1983, 1984, 1986 e 1987 foram muito representativas, pois foram registrados mais de um evento em cada um dos referidos anos. Os eventos de maior intensidade e/ou perdas foram os ocorridos em julho de 1983, maio de 1984 e abril 1987, quando foi decretado situação de emergência. 
Na década de 90, os anos de 1990,1993, 1997 e 1998 são os mais representativos com ocorrência de mais de um evento cada ano. No ano de 1997, foram registrados dois eventos onde foi decretado situação de emergência.

Nos anos 2000, cabe ressaltar os eventos ocorridos em 2001, 2002 e 2009. No ano de 2002, são registrados quatro eventos em que um deles apresenta registro de situação de emergência. Em 2009, há também registro de situação de emergência na cidade.

Dentre os meses mais afetados destaca-se o início do outono, com o mês de abril; e o período de primavera, com mês de novembro (Figura 3), sendo os meses mais significativos quanto aos processos de inundação, em São Gabriel, com ocorrência de seis eventos em abril e sete eventos em novembro.

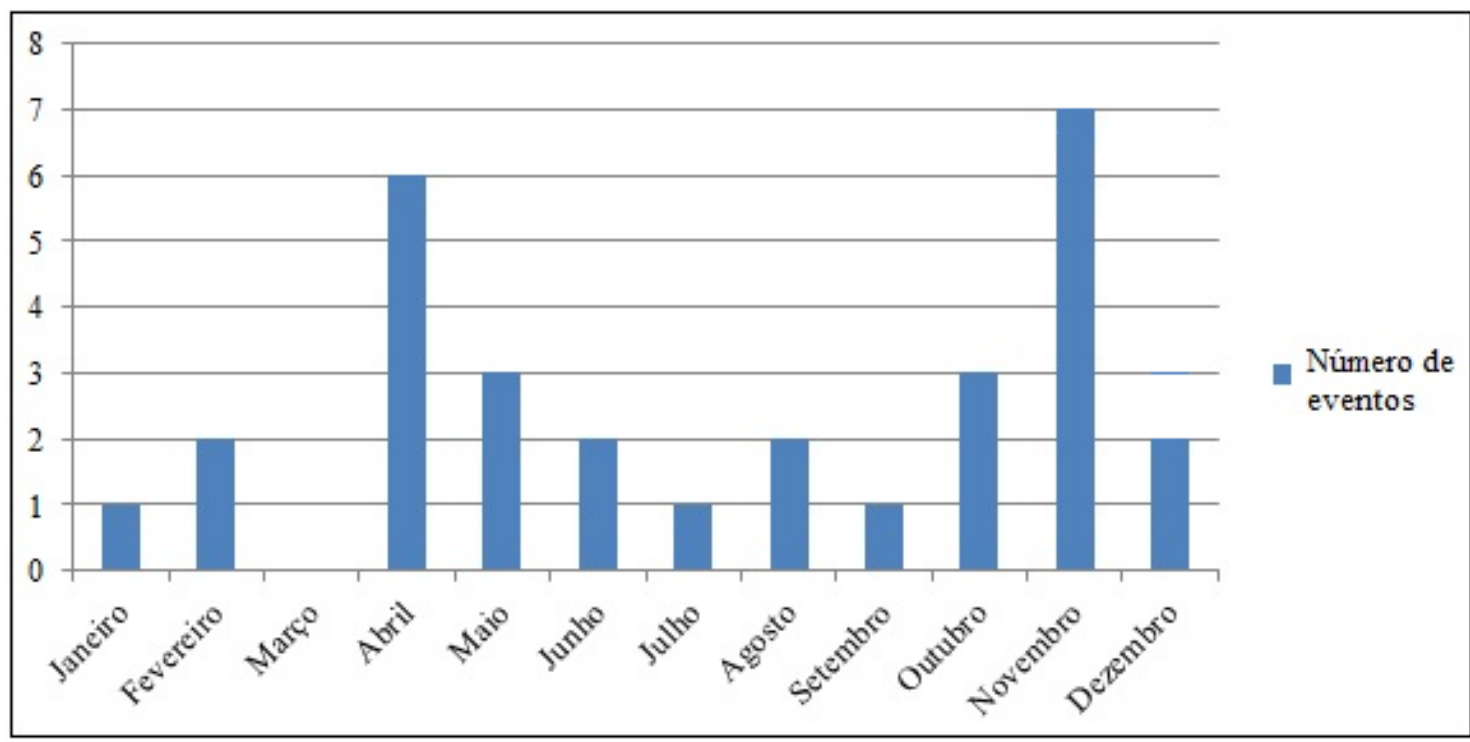

Figura 3. Gráfico de registro mensal dos eventos entre 1980 e 2009.

Dentre as escalas geográficas de clima que são responsáveis pela gênese das inundações, pode-se destacar a escala regional. Esta é responsável pela sucessão de massas de ar e correntes perturbadas. É responsável pela formação das grandes zonas barométricas da Terra, às quais estão ligadas a formação do fenômeno El Niño. 
Com a ocorrência deste evento, é sabido que o Anticiclone Tropical Atlântico (ATA) fortalece-se e impede, em muitos casos, o avanço das frentes polares para latitudes mais baixas, podendo permanecer por vários dias sobre o território gaúcho e, em algumas situações gerar inundações (CPTEC-INPE, 2013).

Nesse sentido, o quadro 5 apresenta uma relação entre os anos com ocorrência de inundações em São Gabriel e os anos nos quais foi registrada a atuação do fenômeno El Niño, no período de 1980 a 2009 , bem como sua intensidade.

\begin{tabular}{|c|c|}
\hline Ano de Registro de Inundação & Intensidade do El Niño \\
\hline 1983 & Forte \\
\hline 1984 & - \\
\hline 1986 & Moderado \\
\hline 1987 & Moderado \\
\hline 1990 & Forte \\
\hline 1993 & Forte \\
\hline 1994 & Moderado \\
\hline 1997 & Forte \\
\hline 1998 & Forte \\
\hline 2002 & Moderado \\
\hline 2009 & Forte \\
\hline
\end{tabular}

Quadro 5. Anos de ocorrência de inundação e intensidade do evento El Niño.

Percebe-se que os anos que registraram importantes inundações, tiveram associação com anos cujo fenômeno El Niño estava atuando com intensidade forte a moderada. O evento ocorrido no ano de 1990, por exemplo, marcou uma das maiores cotas do rio Vacacaí com $810 \mathrm{~cm}$ acima do leito normas, apresentando situação de emergência na cidade. No ano deste evento o fenômeno El Niño apresentou intensidade forte.

Nos anos de 1997, 1998 e 2009 o fenômeno El Niño atuou com intensidade forte, assim como, foram registradas altas cotas do rio junto à cidade de São Gabriel. O ano de 1997 está na faixa de transição dos eventos de La Niña e El Niño. O mês de dezembro deste ano apresenta dentro da escala 
considerada, valores altos indicando uma intensidade forte neste período. O mesmo ocorre no ano de 2009, em que o evento registrado no mês de novembro apresenta intensidade forte do fenômeno.

O ano de 2002 também apresenta influência do fenômeno El Niño. Os eventos ocorreram neste ano nos meses de setembro e dezembro e, segundo a escala intensidade do fenômeno, este ano apresenta uma intensidade moderada. Assim como, em que os meses registrados apresentam registro de intensidade moderada, sendo este um ano de transição do fenômeno La Niña para o fenômeno El Niño.

Além disso, sabe-se que o fenômeno El Niño não possui atuação durante todo o decorrer de um ano, mas sim, em alguns meses do ano, que comumente não são os mesmos meses a cada manifestação do fenômeno, apesar de Berlato e Fontana (2003) destacarem que o período de maior influência do fenômeno sobre a precipitação do estado, é de outubro a dezembro, principalmente nos meses de outubro e novembro. Em menor intensidade, também ocorre influência no período de abril a junho. Isso corrobora com os meses verificados com maior número de eventos de inundação, na cidade de São Gabriel, que foram novembro com sete eventos registrados e abril com o total de seis eventos, como foi mostrado anteriormente no gráfico da figura 3.

Espacialmente, identificou-se os bairros mais atingidos, que são: Vila Maria, Baltar e Menino Jesus, como mostra o mapa na figura 4. 
ÁREA URBANA DE SÃO GABRIEL - RS

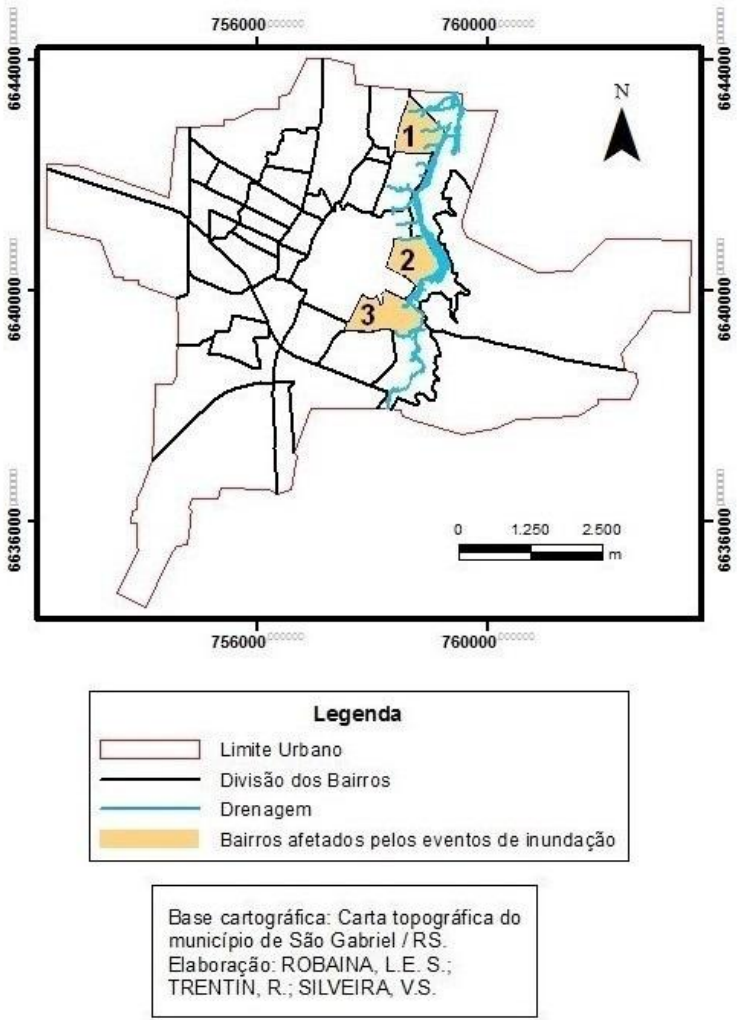

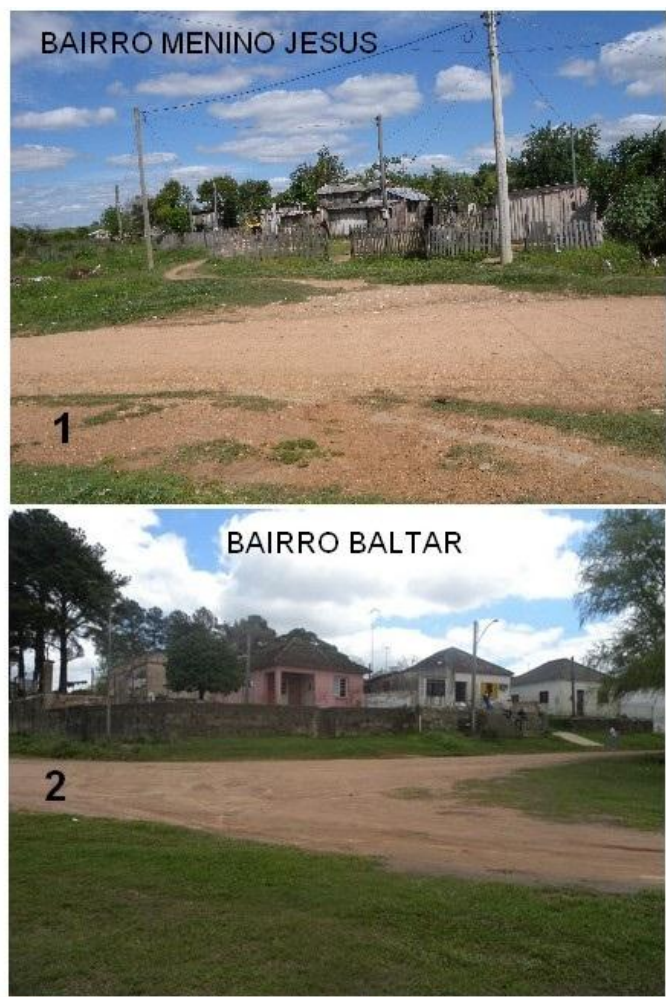

BAIRRO VILA MARIA

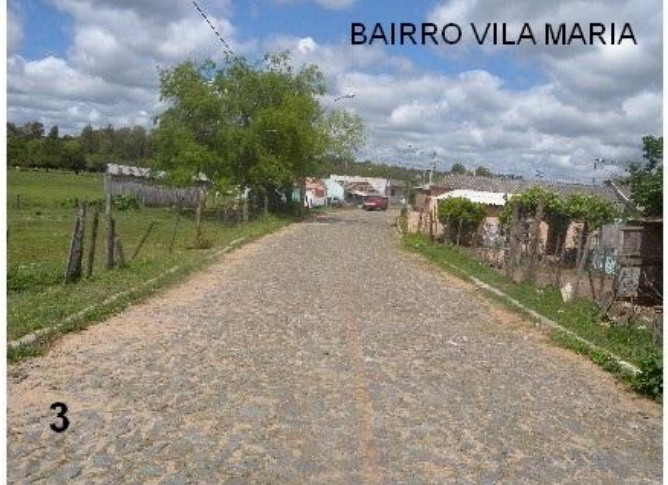

Figura 4. Mapa de localização dos bairros atingidos por inundação.

Nos bairros atingidos definiu-se o zoneamento de risco através dos trabalhos de campo. Nesse zoneamento foi identificada uma área de baixo risco de inundações localizada no bairro Vila Maria, onde os parâmetros de perigo e a vulnerabilidade são caracterizados como baixos, ocupando uma área de $0,20 \mathrm{~km}^{2}$, ou seja, nestas áreas existe uma baixa probabilidade de ocorrência de inundações e são esperadas baixas consequências de danos e prejuízos.

A área com médio risco a inundações ocupa área de $0,03 \mathrm{~km}^{2}$, está localizada no bairro Baltar. Nessas áreas existe baixa probabilidade de ocorrência de inundações e são esperadas médias ou altas consequências de danos e prejuízos dependendo da vulnerabilidade da população residente. 
As áreas com alto risco a inundações ocupam área de $0,11 \mathrm{~km}^{2}$, localizando-se no bairro Baltar e bairro Menino Jesus. Caracterizam-se como áreas urbanas com alta probabilidade de ocorrência de inundações e onde são esperadas médias consequências de danos e prejuízos pela maior capacidade, relativa, da população em enfrentar o problema.

A área definida como muito alto risco a inundações, ocupa área de $0,02 \mathrm{~km}^{2}$. Está representado por uma área com o mais baixo padrão de moradias, localizada no bairro Menino Jesus, onde a área urbana aproxima-se mais da margem direita do Rio Vacacaí. Nessas áreas existe uma alta probabilidade de ocorrência de inundações e são esperadas altas ou muito altas consequências de danos a prejuízos a população dado sua vulnerabilidade.

A distribuição espacial do zoneamento das áreas com risco de inundação, na área urbana de São Gabriel, pode ser observada no mapa da Figura 5. 


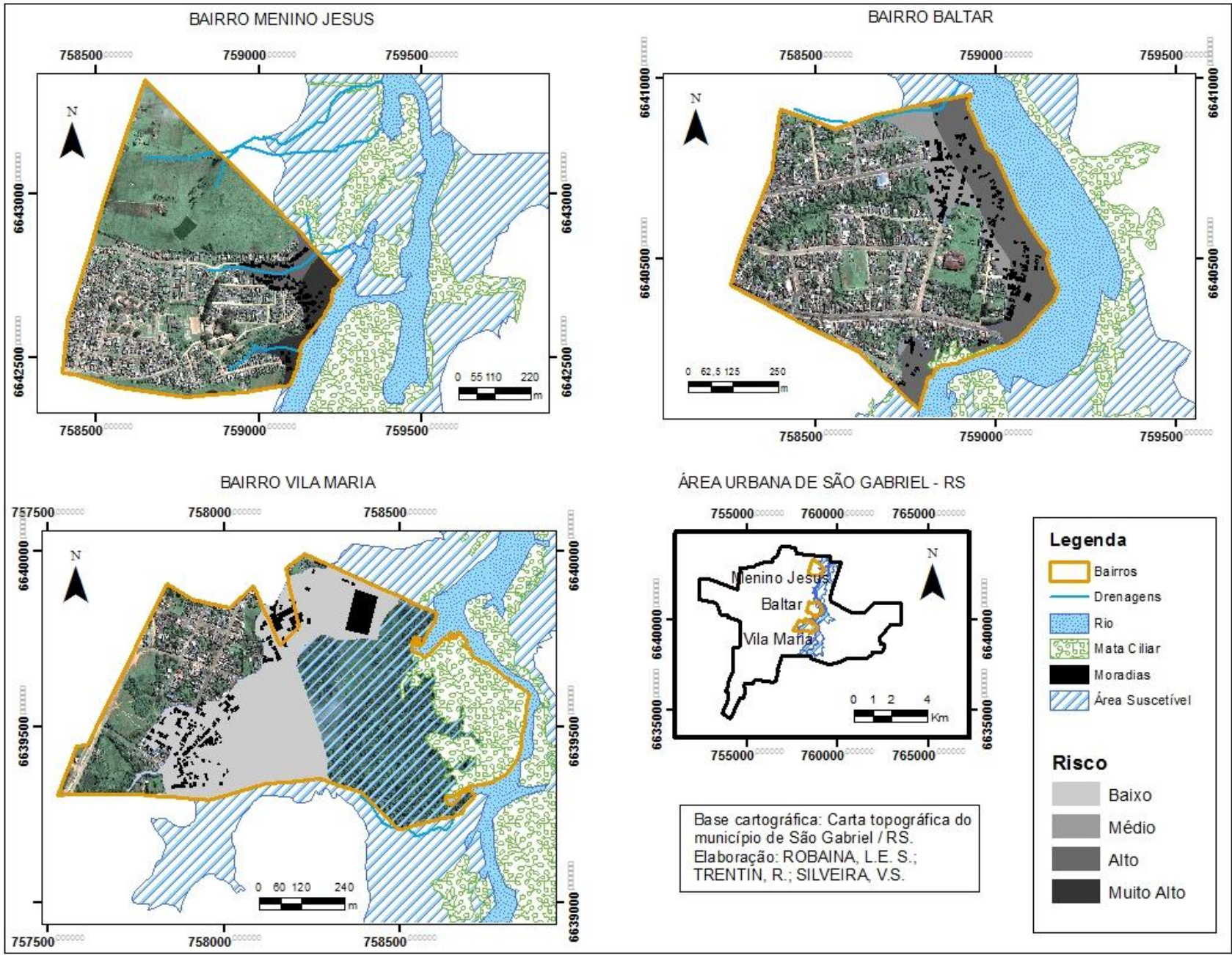

Figura 5. Mapa das áreas com risco de inundações.

\section{Caracterização hidrológica}

Esta análise busca relacionar os dados de precipitação de estações pluviométricas no município de São Gabriel, com dados de cota de uma estação fluviométrica no rio Vacacaí, como mostra a tabela do quadro 6 com os dados dos eventos analisados no trabalho ao longo de 29 anos.

Os eventos de inundação na cidade de São Gabriel ocorrem ao redor da cota de $500 \mathrm{~cm}$ acima do leito normal, como 502cm em 09 de maio de 1984 (figura 6), nos dias 6 e 7 deste período a precipitação chegou próximo a 57 e $37 \mathrm{~mm}$ (Figura 7), respectivamente. No dia 25 de abril de 1991 onde ocorre um evento de inundação com o rio atingindo a cota de $540 \mathrm{~cm}$ e em novembro de 1993 com cota máxima de $574 \mathrm{~cm}$, em outubro de 2001 com cota máxima de $541 \mathrm{~cm}$. 
As cotas máximas que ocasionam eventos de inundação estão entorno de $700 \mathrm{~cm}$, como pode-se notar nas ocorrências de praticamente todas as inundações pesquisadas, porém, a maior cota registrada em um evento é de $810 \mathrm{~cm}$ no ano de 1990. Este evento apresenta características de inundação brusca, pois houve uma chuva intensa e concentrada resultando em 103mm de precipitação em um só dia.

Com relação às características das inundações na cidade há uma equilibrada divisão, ou seja, há inundações graduais em que a precipitação se prolonga por 3 a 4 dias causando problemas as população ribeirinhas. E logo, as inundações bruscas que podem estar relacionadas a uma forte influência do fenômeno El Niño no ano do evento, como por exemplo nos anos de 1990, 1997 e 1998. Outra informação importante está nos dados de precipitação, pois em uma chuva concentrada de aproximadamente 80mm já é possível causar inundação.

\begin{tabular}{|c|c|c|c|c|c|}
\hline Ano & Mês & $\begin{array}{c}\text { Cota máxima } \\
\text { atingida }\end{array}$ & $\begin{array}{c}\text { Precipitação } \\
\text { acumulada }\end{array}$ & $\begin{array}{c}\text { Estação } \\
\text { pluviométrica }\end{array}$ & $\begin{array}{c}\text { Dias das } \\
\text { precipitações } \\
\text { acumuladas }\end{array}$ \\
\hline 198 & Maio & $502 \mathrm{~cm}$ & $94 \mathrm{~mm}$ & 03053019 & 06 e 07 \\
\hline 4 & Maio & $738 \mathrm{~cm}$ & $160 \mathrm{~mm}$ & 03053019 & 20,21 e 22 \\
\hline $\begin{array}{c}198 \\
6 \\
\end{array}$ & Abril & $744 \mathrm{~cm}$ & $130 \mathrm{~mm}$ & 03054018 & 11 a 14 \\
\hline $\begin{array}{c}199 \\
0\end{array}$ & Novembro & $810 \mathrm{~cm}$ & $103 \mathrm{~mm}$ & 03054018 & 04 \\
\hline $\begin{array}{c}199 \\
1 \\
\end{array}$ & Abril & $540 \mathrm{~cm}$ & $137 \mathrm{~mm}$ & 03054018 & 22 a 25 \\
\hline $\begin{array}{c}199 \\
3 \\
\end{array}$ & Novembro & $574 \mathrm{~cm}$ & $119 \mathrm{~mm}$ & 03054018 & 17 a 22 \\
\hline $\begin{array}{c}199 \\
7 \\
\end{array}$ & Dezembro & $787 \mathrm{~cm}$ & $127 \mathrm{~mm}$ & 03054018 & 31 \\
\hline $\begin{array}{c}199 \\
8 \\
\end{array}$ & Junho & $735 \mathrm{~cm}$ & $130 \mathrm{~mm}$ & 03054018 & 09,10 e 11 \\
\hline $\begin{array}{c}200 \\
1 \\
\end{array}$ & Outubro & $541 \mathrm{~cm}$ & $\begin{array}{r}94 \mathrm{~mm} ; \\
69 \mathrm{~mm} \\
\end{array}$ & $\begin{array}{r}03054018 \\
03053004\end{array}$ & 01 a 06 \\
\hline \multirow{3}{*}{$\begin{array}{c}200 \\
2\end{array}$} & Setembro & $712 \mathrm{~cm}$ & $\begin{array}{r}87 \mathrm{~mm} ; \\
79 \mathrm{~mm} \\
\end{array}$ & $\begin{array}{r}03054018 \\
03053004 \\
\end{array}$ & 12 \\
\hline & Novembro & $699 \mathrm{~cm}$ & $\begin{array}{l}82 \mathrm{~mm} ; \\
137 \mathrm{~mm}\end{array}$ & $\begin{array}{r}03053004 ; \\
03054018 \\
\end{array}$ & 21 \\
\hline & Dezembro & $768 \mathrm{~cm}$ & $\begin{array}{l}96 \mathrm{~mm} ; \\
123 \mathrm{~mm}\end{array}$ & $\begin{array}{r}03053004 ; \\
03054018 \\
\end{array}$ & 01 e 02 \\
\hline
\end{tabular}




\begin{tabular}{|c|c|c|c|c|c|}
200 & Novembro & $743 \mathrm{~cm}$ & $\begin{array}{r}118 \mathrm{~mm} ; \\
89 \mathrm{~mm}\end{array}$ & $03054020 ;$ & 21,22 e $23 ;$ \\
& & 83054018 & 19 \\
\hline
\end{tabular}

Quadro 6. Relação dos dados de precipitação e cota no município de São Gabriel.

Para melhor caracterização dos eventos definiu-se 03 eventos significativos, de 1984, 1990 e 2009, para apresentar os dados de precipitação e hidrológicos.

No evento em maio de 1984, a precipitação, medida pela estação 03053019, nos dias 20, 21 e 22 apresentou 37, 56 e $67 \mathrm{~mm}$, respectivamente (Figura 7). Assim, o rio atingiu a cota de $738 \mathrm{~cm}$, no dia 23, como mostra o gráfico da figura 6 , subindo $500 \mathrm{~cm}$ em seis dias, sendo necessário estabelecer decreto de emergência.

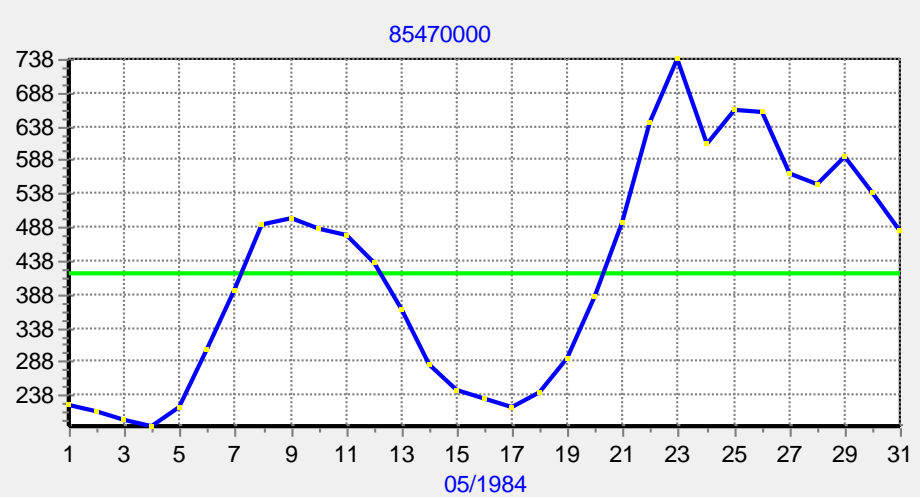

Figura 6. Gráfico com as cotas registradas em maio de 1984 pela estação 85470000.

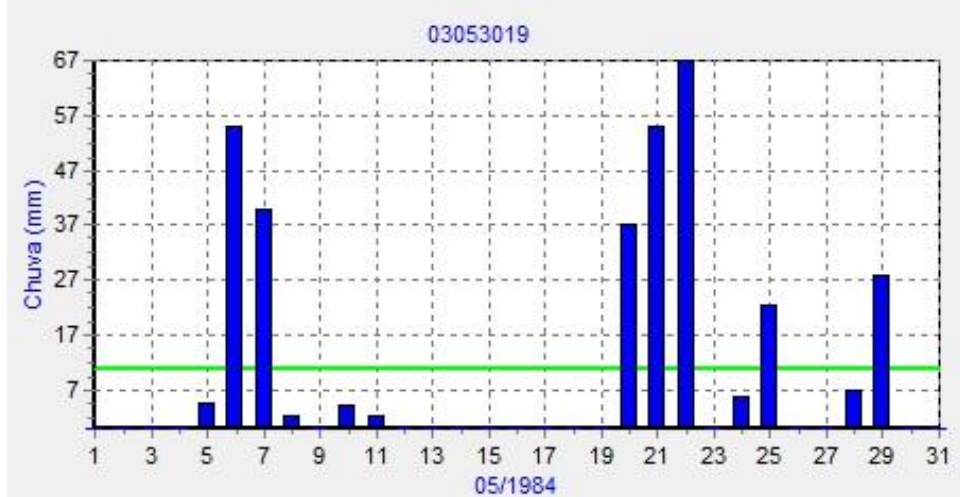

Figura \%. Gráfico com as precipitações registradas em maio de 1984 pela estação 03053019.

Em novembro de 1990 o rio atingiu uma cota máxima de $810 \mathrm{~cm}$, sendo um dos eventos mais significativos dentro do histórico de inundação da cidade de São Gabriel (Figura 8). O evento se 
caracterizou como uma inundação brusca, pois a elevação das águas de $600 \mathrm{~cm}$ ocorreu em três dias.

Este evento gerou a necessidade de ser decretada Situação de Emergência na cidade.

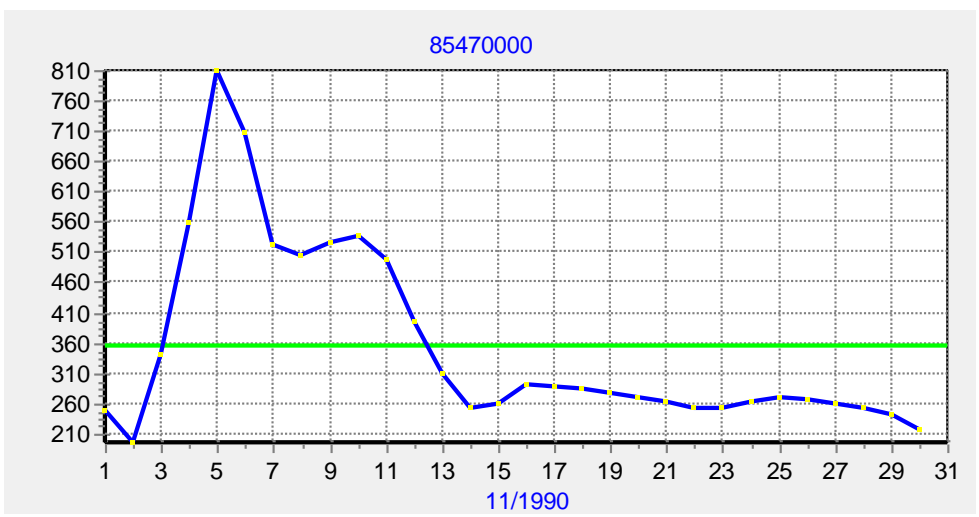

Figura 8. Gráfico com as cotas registradas em novembro de 1990 pela estação 85470000.

Neste evento, quanto à precipitação, o gráfico mostra a grande quantidade de chuva registrada no dia 04 com $103 \mathrm{~mm}$, confirmando o registro de inundação brusca em que a cota máxima foi registrada do dia 05 (Figura 9). No ano deste evento o fenômeno El Niño apresentou intensidade forte.

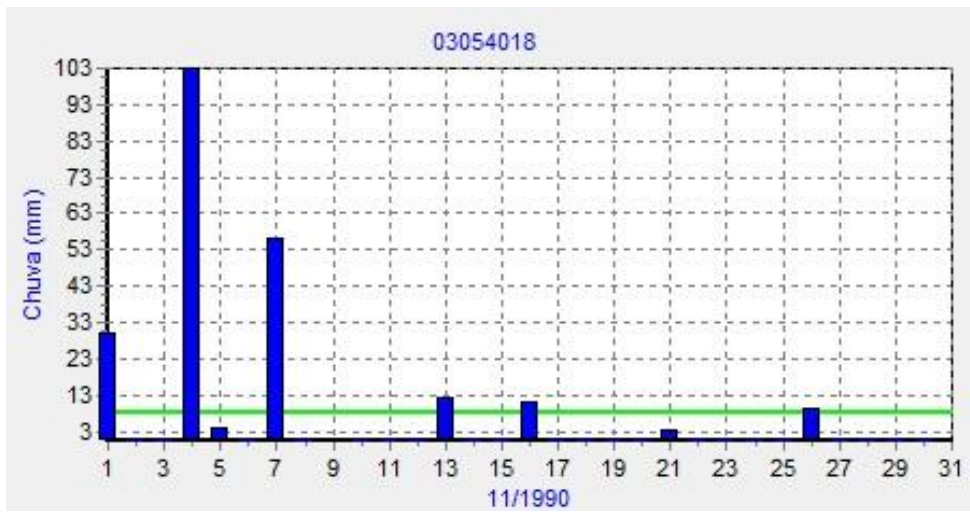

Figura 9. Gráfico com as precipitações registradas em novembro de 1990 pela estação 03054018.

No mês de dezembro de 2009, no dia 16 a cota aparece elevada, acima dos $500 \mathrm{~cm}$, que provoca problemas nas áreas ribeirinhas. Mas é no dia 19 que a inundação causa os maiores prejuízos quando atinge a cota máxima de $743 \mathrm{~cm}$ (Figura 10). 
Durante alguns dias a cota permaneceu alta e apenas no final do mês tende a baixar como mostra 0 gráfico da figura 10. Em 2009, o evento El Niño influência os eventos de precipitação com uma intensidade forte.

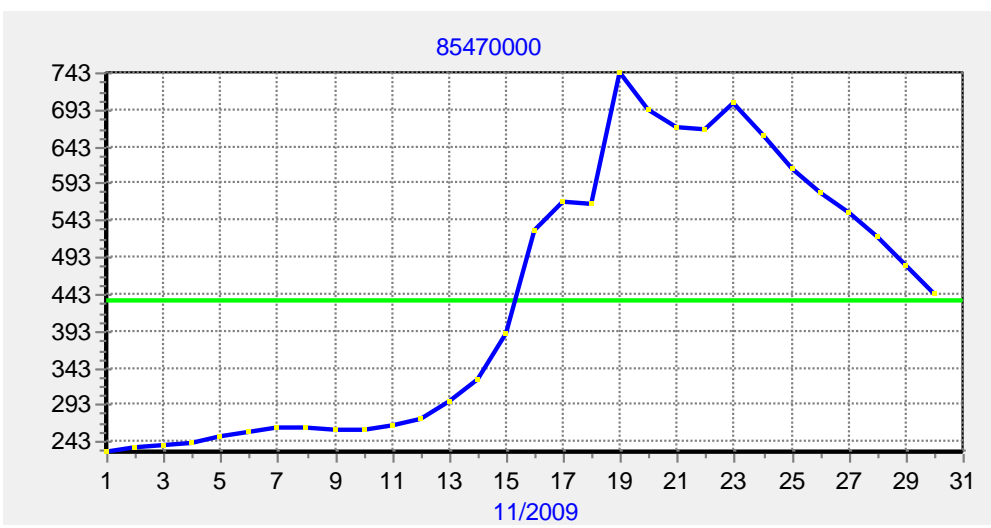

Figura 10. Gráfico com as cotas registradas em dezembro de 2009 pela estação 85470000.

\section{CONSIDERAÇÕES FINAIS}

A partir destes levantamentos de dados e a análise quanto aos processos de inundações ocorridas no município de São Gabriel, no Estado do Rio Grande do Sul, com os dados coletados no site do Hidroweb da Agência Nacional de Águas (ANA) e notícias dos eventos no Jornal Imparcial, jornal de circulação no município; foi possível compreender melhor a dinâmica destes eventos no mesmo.

A partir destas análises verificaram-se eventos importantes, como por exemplo, o evento que ocorreu em maio de 1984 em que o rio Vacacaí atingiu $502 \mathrm{~cm}$. Com isso, sabe-se a menor cota em que um evento é confirmado. Assim, este evento marca a menor cota atingida para que ocorra evento de inundação na cidade.

Outro evento importante é o ocorrido em novembro de 1990, que se mostra um dos mais significativos dentro do histórico de inundação da cidade de São Gabriel por apresentar uma das mais altas cotas de elevação das águas do rio Vacacaí, sendo que esta atingiu $810 \mathrm{~cm}$. 
Portanto, entender dinâmica com que as inundações costumam ocorrer na área urbana do município de São Gabriel tem grande importância para as ações de gestão e planejamento que devem buscar eliminar e/ou mitigar as perdas.

\section{REFERÊNCIAS}

AGÊNCIA NACIONAL DE ÁGUAS (ANA). Disponível em: <www.ana.gov.br/> Acesso em: 10 abr. 2013.

CASTRO, Antônio Luiz Coimbra de. Manual de Desastres. Brasília: [s.n.], 2003.

CENTRO DE PREVISÃO DE TEMPO E ESTUdos Climáticos (CPTEC-INPE). Disponível em: < http://www.cptec.inpe.br/> Acesso em: 29 jul. 2013.

CLIMATE PREDICTION CENTER (CPC). Disponível em:< http://www.cpc.ncep.noaa.gov> Acesso em: 06 set. 2013.

FREITAS, Rafael Bilhan. Inundações no Rio Grande do Sul: Estudos na Cidade de Alegrete. In: Congresso Brasileiro sobre Desastres Naturais, 2012, Rio Claro. Anais... Rio Claro: UNESP, 2012.

INSTITUTO BRASILEIRO DE GEOGRAFIA E ESTATÍSTICA (IBGE). Censo 2010. Disponível em: < http://www.censo2010.ibge.gov.br/> Acesso em: 26 abr. 2013.

MINISTÉRIO DAS CIDADES / INSTITUTO DE PESQUISAS TECNOLÓGICAS - IPT. Mapeamento de riscos em encostas e margens de rios. Brasília: Ministério das Cidades; Instituto de Pesquisas Tecnológicas - IPT, 2007.

PREFEITURA MUNICIPAL DE SÃO GABRIEL. Plano diretor do município de São Gabriel. Disponível em: < http://www.sãogabriel.rs.gov.br> Acesso em: 26 abr. 2013.

RECKZIEGEL, Bernadete Weber. Levantamento dos Desastres Desencadeados por Eventos Naturais Adversos no Estado do Rio Grande do Sul no Período de 1980 a 2005. 2007. Dissertação (Mestrado em Geografia) - Programa de Pós-Graduação em Geografia, UFSM, Santa Maria - RS. 